\title{
Psoriasis and metabolic syndrome: hospital based cross sectional study of prevalence and correlation in a rural south Indian population
}

\author{
Dhanalakshmi Kathirvel*, Vaishnavi Dhandapani, Baskaran R., Gladius Jennifer H.
}

Department of Dermatology, Karpaga Vinayaga Institute of Medical Sciences and Research Centre, Kanchipuram, Tamilnadu, India

Received: 27 August 2016

Accepted: 06 September 2016

\section{*Correspondence:}

Dr. Dhanalakshmi Kathirvel,

E-mail: drdhanuk@gmail.com

Copyright: ( ) the author(s), publisher and licensee Medip Academy. This is an open-access article distributed under the terms of the Creative Commons Attribution Non-Commercial License, which permits unrestricted non-commercial use, distribution, and reproduction in any medium, provided the original work is properly cited.

\section{ABSTRACT}

Background: Psoriasis is a chronic inflammatory skin disease that affects $1-3 \%$ of the population. Recent studies have reported that psoriasis is associated with metabolic disorders, including obesity, dyslipidaemia and diabetes. The aim of the present study was to investigate the prevalence of metabolic syndrome (MS) in psoriasis and to evaluate the association with severity and duration of psoriasis

Methods: This was a hospital based cross sectional study that involved 60 patients with psoriasis evaluated for MS. Statistical analysis was done by SPSS version 16.0 software. Percentages, mean, standard deviation, correlation, chisquare test, $\mathrm{t}$ test were calculated at $5 \%$ level of significance.

Results: $20 \%$ of patients had MS which is comparable to the normal population. $60 \%$ of the patients in our study are obese which is directly correlating with MS. There is significant increase in MS as age $(\mathrm{p}=0.01)$, duration of psoriasis $(\mathrm{p}=0.03)$, BMI $(\mathrm{p}=0.0001)$, waist circumference $(\mathrm{p}=0.0001)$ increases.

Conclusions: There is $20 \%$ association of psoriasis with MS. There is no gender predisposition and no association between the severity of psoriasis and metabolic syndrome. There is minimal relationship between the duration of psoriasis and metabolic syndrome. Obesity is the commonest factor related to psoriasis, diabetes and MS which should be taken care of by diet, exercise and lifestyle modification.

Keywords: Psoriasis, Metabolic syndrome, Dyslipidaemia

\section{INTRODUCTION}

Psoriasis is a chronic inflammatory skin disease that affects $1-3 \%$ of the population. ${ }^{1}$ In 1988, Reaven proposed the term "syndrome $\mathrm{X}$ " for the combination of glucose intolerance, hypertension, hyperinsulinemia, high-density lipoprotein (HDL) cholesterol, high triglyceridimea and hypertension. In 1991, De Fronzo named the clustering of metabolic disorders, including non-insulin-dependent DM, obesity, hypertension, lipid abnormalities and atherosclerotic cardiovascular disease as "insulin resistance syndrome", 2

Moreover, psoriasis has been shown to be an independent risk factor for myocardial infarction, particularly in young patients, and severe psoriasis has been shown to be associated with increased mortality in patients with cardiovascular disease. This comprehensive concept of metabolic syndrome is of clinical significance because it can be a strong predictor of cardiovascular diseases, diabetes, and stroke. ${ }^{3}$

The prevalence of metabolic syndrome is increasing (30$40 \%$ ) in part paralleling the rising prevalence of obesity worldwide. Systemic inflammation is associated with metabolic syndrome, with T helper cell type 1 (Th-1) proinflammatory cytokines such as tumor necrosis factor $\alpha$ and non-specific measures of inflammation such as $\mathrm{C}$ reactive protein levels being elevated compared to those without the metabolic syndrome However, there is a 
limited understanding of the relationship between chronic inflammatory diseases and the prevalence of metabolic syndrome. ${ }^{4}$

The association between psoriasis and metabolic syndrome is also true for mild severity psoriasis and is independent from the tendency of psoriatic patients to be obese. ${ }^{1}$ Yet despite numerous studies linking psoriasis and cardiovascular disease, translating these studies into clinical guidelines has been hampered by the lack of accurate cardiovascular risk prediction in the psoriasis population. $^{5}$

Aim of the present study was to investigate the prevalence of MS in psoriasis and to evaluate the association with severity and duration of psoriasis.

\section{METHODS}

\section{Study design}

The study was a hospital based cross sectional study conducted in the outpatient department of dermatolgy.

\section{Eligibility criteria}

60 patients diagnosed as psoriasis who are more than 18 years were included in the study.

\section{Data collection}

After obtaining the informed consent, all patients were subjected to detailed history taking and clinical examination. A detailed history taking included duration of the disease, joint pains, smoking, alcohol consumption, diet, presence of other systemic illness, past intake of systemic agents for psoriasis and concomitant intake of medicines for other illnesses. Clinical examination included measurement of height, weight, waist circumference, hip circumference and blood pressure.

The body mass index (BMI) was by weight in $\mathrm{kg} / \mathrm{square}$ of height in meters. According to Indian guidelines, a BMI from 23 to 24.9 is overweight, a BMI greater than or equal to 25 is moderate obesity and a BMI greater than or equal to 30 is severe obesity.

The waist circumference was measured by placing the measuring tape snugly around the abdomen at the level of the iliac crest. A waist circumference of more than $90 \mathrm{~cm}$ and $80 \mathrm{~cm}$ for men and women, respectively, was considered as abdominal obesity. The blood pressure was taken in the sitting posture and the average of two measurements was recorded.

Extent of involvement was assessed by body surface area affected by psoriasis: mild $<5 \%$ of the surface area; moderate $5-30 \%$; and severe $>30 \%$. Psoriasis area and severity index (PASI) is also calculated.
All patients underwent Serum glucose levels, lipid profile which included total cholesterol, low density lipoprotein (LDL), high density lipoprotein (HDL) and triglyceride levels and Liver function test. Patients were considered to have diabetes if their fasting glucose was more than or equal to $100 \mathrm{mg} / \mathrm{dl}$.

MS was diagnosed using the South Asian Modified National Cholesterol Education Program Adult Treatment Panel III criteria (SAM-NCEP criteria). ${ }^{5}$

If three or more of the following were present, the patient was diagnosed as having MS:

- Abdominal obesity (definition of abdominal obesity was modified using Asia Pacific WHO guidelines as waist circumference $\geq 90 \mathrm{~cm}$ for males and $\geq 80 \mathrm{~cm}$ for females),

- $\quad$ Blood pressure $>130 / 85 \mathrm{mmHg}$,

- Fasting blood glucose $\geq 100 \mathrm{mg} / \mathrm{dl}$,

- Hypertriglyceridemia $>150 \mathrm{mg} / \mathrm{dl}$, or low HDL cholesterol ( $<40 \mathrm{mg} / \mathrm{dl}$ for males and $<50 \mathrm{mg} / \mathrm{dl}$ for females).

- BMI was calculated and was substituted for obesity

\section{Statistical analysis}

Data entry and analysis was done using statistical package for social sciences (SPSS) version 16.0 software. Percentages, mean, standard deviation, correlation, chisquare test, $\mathrm{t}$ test were calculated at 5\% level of significance.

\section{RESULTS}

Our study included 60 patients which include $40(66.7 \%)$ males and $20(33.3 \%)$ females. Age at the time of first visit varied from minimum of 23 years to maximum of 65 years with mean age of 42.07 years. We found there is increase in age is proportionate to the appearance of metabolic syndrome. Duration of psoriasis varied from 2 months to 20 years with the mean duration of about 5.283 years. Duration of psoriasis has significant positive correlation with the severity of psoriasis as shown in Table 1 .

Percentage of body involvement is measured by BSA and PASI. According to BSA involvement, psoriasis is divided into 3 grades- mild $-<10 \%$ involvement $n=20$ $(33.3 \%)$, moderate- $10-30 \%$ involvement $n=12(20 \%)$ and severe $>30 \%$ involvement $\mathrm{n}=28(46.7 \%)$. PASI calculated is ranging from 8 to 108 with mean of 49.3. According to BMI, patients were categorized into 4 groups include, normal $8(13.3 \%)$, overweight $16(26.7 \%)$, moderate obesity $26(43.3 \%)$ and severe obesity $10(16.7 \%) .60 \%$ of the patients in our study are obese which is directly correlating with metabolic syndrome as seen in Figure 1. 
Table 1: Descriptive characteristics of the study population.

\begin{tabular}{|c|c|c|}
\hline Variable & Mean \pm SD & Min-Max. \\
\hline $\operatorname{Sex}$ M/F (\%) & $40(66.7) / 20(33.3)$ & \\
\hline $\begin{array}{l}\text { Age @ } \\
\text { enrolment }\end{array}$ & $42.07 \pm 9.485$ & $23-65$ \\
\hline $\begin{array}{l}\text { Duration of } \\
\text { psoriasis }\end{array}$ & $5.283 \pm 4.28$ & $\begin{array}{l}2 \text { months - } \\
20 \text { years }\end{array}$ \\
\hline BSA & $24.3 \pm 17.15$ & $3-52$ \\
\hline PASI & $49.33 \pm 32.506$ & $8-108$ \\
\hline $\begin{array}{l}\text { BMI (mean } \\
\pm \text { SD) }\end{array}$ & $26.55 \pm 5.308$ & $19-42$ \\
\hline $\begin{array}{l}\text { Waist } \\
\text { circumference }\end{array}$ & $95.6 \pm 14.64$ & $68-132$ \\
\hline Waist /hip ratio & $1.04 \pm 0.046$ & $1-1$ \\
\hline $\begin{array}{l}\text { HDL }<40 \text { in } \\
\text { females; }<50 \text { in } \\
\text { males }\end{array}$ & $53.97 \pm 7.985$ & $39-71$ \\
\hline $\begin{array}{l}\text { Triglycerides } \\
>150 \mathrm{mg} / \mathrm{dl}\end{array}$ & $108.93 \pm 29.96$ & $60-172$ \\
\hline $\begin{array}{l}\text { Blood pressure } \\
>135 / 85\end{array}$ & $\begin{array}{l}120.8 \pm 13.67 / \\
80.27 \pm 8.84\end{array}$ & $\begin{array}{l}100 / 60 \text { to } \\
150 / 90\end{array}$ \\
\hline $\begin{array}{l}\text { Fasting blood } \\
\text { sugar } \geq 100 \mathrm{mg} / \mathrm{dl}\end{array}$ & $113.03 \pm 58.736$ & $62-341$ \\
\hline $\begin{array}{l}\text { Metabolic } \\
\text { syndrome }\end{array}$ & $12(20 \%)$ & \\
\hline
\end{tabular}

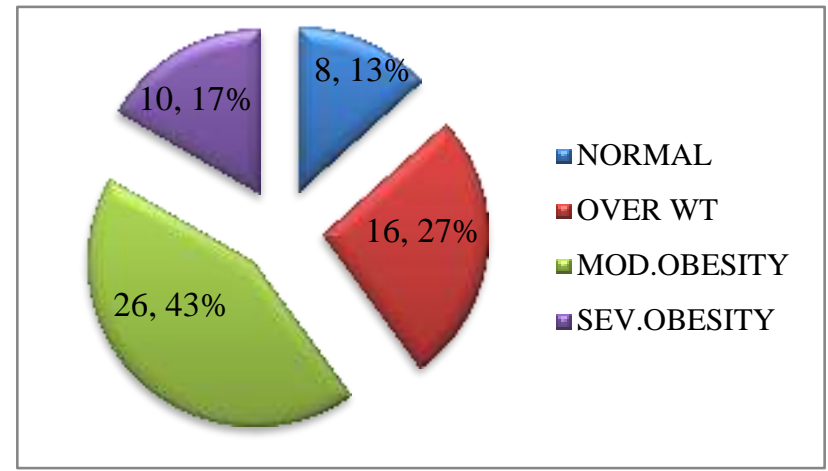

Figure 1: BMI distribution in the study population.

$20(33.3 \%)$ persons were known diabetic at the time of presentation, whether diabetes preceded or psoriasis preceded is not known. In our study we found significant correlation between obesity $(\mathrm{p}=0.405, \mathrm{p}=0.001)$ and diabetes. As the BMI increases, the chance of being diabetes increases. Only $4(6.7 \%)$ persons were hypertensive on regular antihypertensive therapy.

Waist circumference is strongly correlated positively with diabetes mellitus ( $p=0.406, p=0.001)$, obesity $(p=0.722$, $\mathrm{p}=0.0001)$ and dyslipidaemia- increased LDL $(\mathrm{p}=0.419$, $\mathrm{p}=0.001)$.

We found $12(20 \%)$ persons with metabolic syndrome in our study which is comparable to the normal population. We found significant positive correlation with metabolic syndrome and obesity ( $\mathrm{p}=0.581, \mathrm{p}=0.0001)$, hypertension ( $\mathrm{p}=0.597, \mathrm{p}=0.0001)$, triglyceride levels $(\mathrm{p}$ $=0.371, \mathrm{p}=0.003)$, waist circumference $(\mathrm{p}=0.371, \mathrm{p}$ $=0.0001)$ and diabetes mellitus $(\mathrm{p}=0.260, \mathrm{p}=0.004)$ and negative correlation with HDL ( $\mathrm{p}=-0.587, \mathrm{p}=0.0001)$ as given in Figure 2.

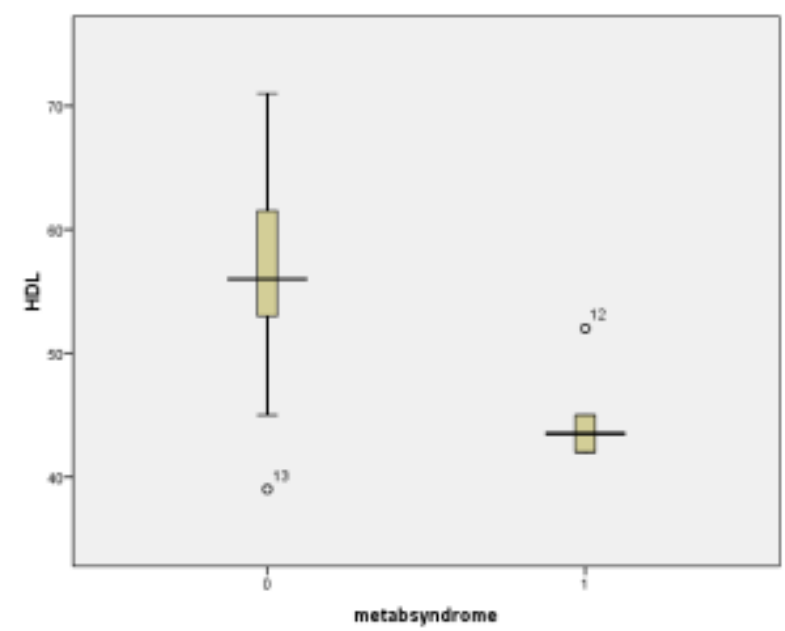

Figure 2: Correlation between HDL and MS

Persons fulfilling criteria for metabolic syndrome 12 (20\%) patients fulfilled $\geq 3,28(46.7 \%)$ fulfilled 2 criteria. Whether these patients with 2 positive criteria will develop metabolic syndrome has to be followed up long term as in Figure 3.

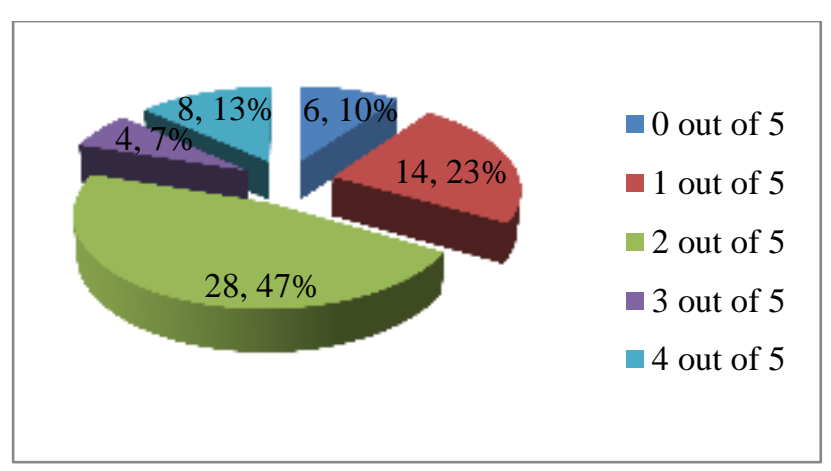

Figure 3: Patients fulfilling the criteria for MS

When comparing both the groups of psoriasis with and without psoriasis, there is significant increase in MS as age $(\mathrm{p}=0.01)$, duration of psoriasis $(\mathrm{p}=0.03)$, BMI ( $\mathrm{p}$ $=0.0001)$, waist circumference $(\mathrm{p}=0.0001)$ increases. We noted there is no gender predisposition, as both males and females are equally affected, but it was more frequent after the age of 40 .

Comparing psoriatic patients with and without metabolic syndrome, we observed that patients with MS had a higher mean age, an earlier age of onset of psoriasis and longer disease duration. There were no differences regarding gender, clinical type of psoriasis, psoriasis severity and prevalence of smokers. 
We noted that presence of impaired fasting glucose is a strong predictor for developing metabolic syndrome in the patients without metabolic syndrome (OR-6, p $=0.017$ ). When comparing both the groups with and without metabolic syndrome, we observed significant correlation between HDL levels, TG and LDL levels and metabolic syndrome.
Cholesterol levels have no significant correlation with metabolic syndrome. There was no correlation between the severity of psoriasis and occurrence of metabolic syndrome. In particular, there was no difference in the prevalence of MS in patients with a PASI score lower or higher than 10 or in patients with BSA involvement lower or greater than $10 \%$ as given in Table 2 .

Table 2: Comparison of psoriatic patients with and without metabolic syndrome.

\begin{tabular}{|lllll|}
\hline Variable & $\begin{array}{l}\text { Psoriasis without metabolic } \\
\text { syndrome }(\mathbf{n}=\mathbf{4 8})\end{array}$ & $\begin{array}{l}\text { Psoriasis with metabolic } \\
\text { syndrome }(\mathbf{n}=\mathbf{1 2})\end{array}$ & $\mathbf{t}$ & $\mathbf{p}$ value \\
\hline Age & $40.42 \pm 9.24$ & $48.67 \pm 7.64$ & 10.218 & 0.0001 \\
\hline DBP & $77.83 \pm 8.25$ & $90 \pm 0.00$ & 8.772 & 0.0001 \\
\hline SBP & $116.83 \pm 12.18$ & $136.67 \pm 4.92$ & 4.569 & 0.0001 \\
\hline BMI & $25.51 \pm 2.78$ & $34.62 \pm 6.76$ & 2.245 & 0.03 \\
\hline Duration & $5.65 \pm 4.69$ & $3.83 \pm 1.53$ & 0.29 & 0.78 \\
\hline BSA & $24.67 \pm 16.52$ & $22.83 \pm 2.26$ & 0.112 & 0.91 \\
\hline PASI & $49.62 \pm 30.05$ & $48.17 \pm 42.51$ & 5.57 & 0.0001 \\
\hline $\begin{array}{l}\text { Waist } \\
\text { circumference }\end{array}$ & $90.62 \pm 9.6$ & $115.5 \pm 14.71$ & 0.676 & 0.50 \\
\hline Waist hip ratio & $1.04 \pm 0.05$ & $1.04 \pm 0.02$ & 2.785 & 0.02 \\
\hline $\begin{array}{l}\text { Fasting blood } \\
\text { sugar }\end{array}$ & $96.12 \pm 17.31$ & $180.67 \pm 104.81$ & 0.942 & 0.36 \\
\hline Serum cholesterol & $176.29 \pm 41.31$ & $193.5 \pm 59.81$ & 5.53 & 0.0001 \\
\hline HDL & $56.29 \pm 7.02$ & $44.67 \pm 3.7$ & 3.75 & 0.0001 \\
\hline TG & $102.38 \pm 24.32$ & $135.17 \pm 36.72$ & 2.26 & 0.03 \\
\hline LDL & $106.89 \pm 41.21$ & $137.5 \pm 45.31$ & & \\
\hline
\end{tabular}

\section{DISCUSSION}

The occurrence of one or multiple disorder(s) in association with a given disease (comorbidity) has recently gained interest in various fields of medicine. Often comorbidity appears to be related to common pathogenetic pathways. In contrast to syndromes, which comprise symptoms that appear synchronously, comorbidities reflect timely unrelated secondary disease involving the same or additional organs. Comorbidities tend to arise from complex disorders, they are frequently multigenic and multifactorial, and most often demonstrate an inflammatory background. Such is the case with psoriasis. Many studies undertaken in western populations highlight the association between psoriasis and diabetes, obesity, dyslipidaemia, and cardiovascular disorders. As a race, Asian-Indians have a higher predisposition to obesity, metabolic syndrome, diabetes, and cardiovascular disorders as compared to western populations. There is a paucity of literature highlighting the association of psoriasis with diabetes, dyslipidaemia, and cardiovascular disorders in Indian populations. ${ }^{7}$

\section{Psoriasis and MS}

As many of the studies conducted in United States, United Kingdom and Europe suggested higher prevalence of metabolic syndrome. Gisondi et al reported that the prevalence of metabolic syndrome was higher in psoriasis patients $(30.1 \%)$ than in patients with general dermatological conditions $(20.6 \%){ }^{8}$ In addition, Sommer et al observed a high prevalence of metabolic syndrome among patients $(4.3 \%)$ with psoriasis than in controls $(1.1 \%)^{9}$

But in a Korean study reported the prevalence of metabolic syndrome in psoriatic patient is $10.3 \%$ and found no association by this two. ${ }^{2}$ Similarly a study conducted in Mumbai by Rickson et al found $18.2 \%$ prevalence of metabolic syndrome which is comparable to the general population. ${ }^{7}$

The overall prevalence of MS is about $30-40 \%$ in the Indian population, with a higher prevalence in South India. ${ }^{10}$ In Punjab study, metabolic syndrome in psoriasis is found to be $25 \% .{ }^{11}$ In our study prevalence of metabolic syndrome in psoriasis to be $20 \%$ which is much lower than other studies conducted in India. In our study we found no relation between the severity of psoriasis with metabolic syndrome which is supported by Gisondi et al, sommer et al and by many other studies and in contrast with Cohen et al. ${ }^{8,9,12}$ In our study there was no association between the duration of psoriasis and MS as with other studies.

\section{Psoriasis and the components of MS}

Obesity was found to be the commonest component in the metabolic syndrome in psoriatic patients in our study as evidenced by increased BMI and increased waist 
circumference but not the waist hip ratio in our study. This supports the hypothesis of adiponectin theory; obesity is the initial event in the association which triggers the development of both psoriasis and metabolic syndrome.

In our study we noted that diabetes increases the risk of developing metabolic syndrome in psoriasis two fold supported by Nigam et al with prevalence of impaired glucose levels $(27.7 \%$ ) as opposed to $33.3 \%$ in our study. $^{13}$

Many studies suggest that dyslipidaemia is the commonest association with psoriasis which is opposed by Rickson et al, shradhha et al and also by our study.,14 But HDL levels are inversely proportional to the occurrence of psoriasis and LDL levels are deranged than that of triglycerides.

In our study, hypertension was not at all significantly associated with metabolic syndrome. An interesting finding in our study is $47 \%$ of the patients fulfilled 2 out 5 criteria for metabolic syndrome which emphasis on the follow up of the patients for longer duration to know the occurrence of metabolic syndrome.

Observational study designs are associated with a number of limitations. These include the cross-sectional nature of this study which does not allow us to determine which developed first, psoriasis or the metabolic syndrome. Secondly, we cannot be certain that psoriasis caused the metabolic syndrome; factors including diet, physical inactivity, alcohol or genetic predisposition which have not been evaluated in this study may be acting as confounding or effect modifying factors in this relationship. This is not case control study, we couldn't determine accurately the association is strong or not.

\section{CONCLUSION}

More than 40 years of age of both sexes are prone to develop metabolic syndrome in persons with psoriasis. Duration of psoriasis not very much related to the development of psoriasis. Severity of psoriasis is not a related factor for metabolic syndrome. As the BMI increases, the risk of developing metabolic syndrome is more. Waist circumference is directly proportional to the BMI. Waist-Hip ratio is not a relevant indicator for the assessment of obesity in Indian population. Concurrent occurrence of diabetes with psoriasis increases the risk of metabolic syndrome two fold.

Almost half of the patients had fulfilled two out of five criteria for metabolic syndrome, so the patients should be followed up further to know the real prevalence of metabolic syndrome.

Invariably all grades of psoriatic patients should undergo all baseline investigations to rule out diabetes mellitus, hypertension and lipid abnormalities to detect the metabolic syndrome early. This study has to be continued for years to know the real prevalence.

\section{ACKNOWLEDGEMENTS}

We acknowledge Keerthana for her contribution in this study and all the patients who gave their willful consent for this study.

\section{Funding: No funding sources}

Conflict of interest: None declared

Ethical approval: The study was approved by the institutional ethics committee

\section{REFERENCES}

1. Nisa N, Qazi MA. Prevalence of metabolic syndrome in patients with psoriasis. Indian $\mathbf{J}$ Dermatol Venereol Leprol. 2010;76:662-5.

2. Iizuka T. Psoriasis and metabolic syndrome. Journal of Dermatology. 2012;39:212-8.

3. Kim GW, Par HJ, Kim HS, Su-Han Kim SH, Ko $\mathrm{HC}$, Kim BS, et al. Analysis of cardiovascular Risk Factors and Metabolic Syndrome in Korean Patients with Psoriasis. Ann Dermatol. 2012;24(1):11-5.

4. Langan SM, Seminara NM, Shin DB, Troxel AB, Kimmel SE , Mehta NN, et al. Prevalence of metabolic syndrome in patients with psoriasis. A population-based study in the United Kingdom. J Invest Dermatol. 2012;132(3):556-62.

5. Mehta NN, Yu YD, Pinnelas R, Krishnamoorthy P, Shin DB, Troxel AB, et al. Attributable Risk Estimate of Severe Psoriasis on Major Cardiovascular Events. Am J Med. 2011;124(8):775.

6. Enas EA, Mohan V, Deepa M, Farooq S, Pazhoor S, Chennikkara H. The metabolic syndrome and dyslipidemia among Asian Indians: A population with high rates of diabetes and premature coronary artery disease. J Cardiometab Syndr. 2007;2:267-75.

7. Rickson RP, Sangeeta TA, Prema KV. A study of prevalence of diabetes, insulin resistence, lipid abnormalities and cardiovascular risk factors in patients with chronic plaque psoriasis. Indian J Dermatol. 2011;56(5):520-6.

8. Gisondi P, Tessari G, Conti A. Prevalence of metabolic syndrome in patients with psoriasis: a hospital-based case-control study. British Journal of Dermatology. 2007;157:68-73.

9. Sommer DM, Jenisch S, Suchan M, Christophers E, Weichenthal M. Increased prevalence of the metabolic syndrome in patients with moderate to severe psoriasis. Arch Dermatol Res. 2006;298:3218.

10. Ramachandran A, Snehalatha C, Satyavani K, Sivasankari S, Vijay V. Metabolic syndrome in urban Asian Indian adults: A population study using modified ATP III criteria. Diabetes Res Clin Pract. 2003;60:199-204. 
11. Malhotra SK, Dhaliwal GS, Puri KJPS, Gambhir ML, Mahajan M. An insight into relationship between psoriasis and metabolic syndrome. Egyptian dermatology Online Journal 2011;7(2):5.

12. Cohen AD, Sherf M, Vidavsky L, Vardy DA, Shapiro J, Meyerovitch J. Association between psoriasis and metabolic syndrome. Dermatology. 2008;216:152-5.

13. Nigam P, Dayal SG. Diabetic status in psoriasis. Indian J Dermatol Venereol Leprol. 1979;4(5):171-4.

14. Madanagobalane S, Anandhan S. Prevalence of metabolic syndrome in south Indian patients with psoriasis and relation between disease severity and metabolic syndrome: A hospital based case-control study. Indian Journal of Dermatology. 2012;57:3537.

Cite this article as: Kathirvel D, Dhandapani V, Baskaran R., Gladius Jennifer H. Psoriasis and metabolic syndrome: hospital based cross sectional study of prevalence and correlation in a rural south Indian population. Int J Res Dermatol 2016;2:4954. 